\title{
Ionospheric delay gradient model for GBAS in the Asia-Pacific region
}

\author{
Susumu Saito ${ }^{1}$ (D) Surendra Sunda ${ }^{2} \cdot$ Jiyun Lee $^{3} \cdot$ Sam Pullen $^{4} \cdot$ Slamet Supriadi $^{5} \cdot$ \\ Takayuki Yoshihara $^{1} \cdot$ Michael Terkildsen $^{6} \cdot$ Frédéric Lecat $^{7} \cdot$ ICAO APANPIRG $^{2}$ \\ Ionospheric Studies Task Force
}

Received: 14 December 2016/Accepted: 28 August 2017/Published online: 12 September 2017

(c) The Author(s) 2017. This article is an open access publication

\begin{abstract}
We investigated characteristics of anomalous spatial gradients in ionospheric delay on GNSS signals in the Asia-Pacific (APAC) low-magnetic latitude region in the context of the ground-based augmentation system (GBAS). The ionospheric studies task force established under the Communications, Navigation, and Surveillance subgroup of International Civil Aviation Organization (ICAO) Asia-Pacific Air Navigation Planning and Implementation Regional Group, analyzed GNSS observation data from the Asia-Pacific region to establish a regionally specified ionospheric threat model for GBAS. The largest ionospheric delay gradient value in the analyzed data was
\end{abstract}

The ICAO APANPIRG Ionospheric Studies Task Force (ISTF) was established by the Communications, Navigation, and Surveillance (CNS) Subgroup under the International Civil Aviation Organization (ICAO) Asia-Pacific Air Navigation Planning and Implementation Regional Group (APANPIRG) in 2011 to facilitate GNSS implementation in the air navigation in the Asia-Pacific region. It was dissolved in 2016 after the successful completion of its tasks.

Susumu Saito

susaito@enri.go.jp

1 Electronic Navigation Research Institute, National Institute of Maritime, Port, and Aviation Technology, Chofu, Tokyo, Japan

2 Airports Authority of India, New Delhi, India

3 Korea Advanced Institute of Science and Technology, Taejon, Republic of Korea

4 Stanford University, Stanford, CA, USA

5 National Institute of Aeronautics and Space in Indonesia, Jakarta, Indonesia

6 Bureau of Meteorology, Melbourne, Australia

7 Asia-Pacific Office, International Civil Aviation Organization, Bangkok, Thailand
$518 \mathrm{~mm} / \mathrm{km}$ at the L1 frequency $(1.57542 \mathrm{GHz})$, observed at Ishigaki, Japan in April 2008. The upper bound on the ionospheric delay gradient for a common ionospheric threat model for GBAS in the ICAO APAC region was determined to be $600 \mathrm{~mm} / \mathrm{km}$, irrespective of satellite elevation angle.

Keywords GNSS ground-based augmentation system (GBAS) · Ionospheric threat model · Ionospheric delay gradient $\cdot$ Low-latitude ionosphere

\section{Introduction}

The ground-based augmentation system (GBAS) provides corrections and integrity information for global navigation satellite system (GNSS) signals to provide navigation guidance for precision approach and landing for civil aviation. GBAS is based on the differential GNSS technique, whereby errors in GNSS range measurements are corrected in the range domain. The corrections delivered in real time are based on measurements by multiple ground reference GNSS receivers usually placed at or near an airport with their locations precisely known. GBAS is now in operation at many airports globally to support Category-I precision approaches. GBAS provides aircraft with differential range corrections for each satellite with an elevation angle higher than $5^{\circ}$ as well as integrity information through VHF Data Broadcast stations. GBAS also provides approach path information. The aircraft in flight then presents the lateral and vertical deviations from the desired approach path to the pilot in-command.

Civil aviation transitions to CAT II and III operations and existing ILS (Instrument Landing System) procedures are gradually replaced or supplemented by GBAS Landing 
System (GLS) procedures. GBAS will increasingly become a safety-critical application of GNSS for civil aviation requiring a high level of accuracy, integrity, continuity, and availability of service. The requirements are defined by the International Civil Aviation Organization (ICAO) (ICAO 2014). Standards for avionics are further refined by relevant standardizing organizations such as RTCA (RTCA 2008a, b)/EUROCAE. EUROCAE also defined minimum operational performance standards for GBAS ground subsystem (EUROCAE 2013). To date, GBAS has been standardized based on the use of single-frequency GNSS $(\mathrm{L} 1$, centered at $1.57542 \mathrm{GHz})$ only.

\section{Impact of the ionosphere on GBAS and mitigation}

The propagation delay of GNSS signals due to the ionosphere is one of the most significant sources of ranging error. Ionospheric delay is proportional to the total number of electrons in a unit area (total electron content, or TEC) along the signal propagation path between a satellite and a receiver. Further, the ionospheric delay is inversely proportional to the square of the signal frequency. We express ionospheric delay in units of meters calculated at the GPS L1 frequency $(1.57542 \mathrm{GHz})$. At the L1 frequency, 0.16 meters of delay is equivalent to 1 TEC Unit (TECU, or $10^{16}$ electrons $/ \mathrm{m}^{2}$ ). In GBAS, the ionospheric delay is corrected as a part of the total ranging error including tropospheric delay, satellite clock error, and satellite ephemeris error from the range measurements recorded by the reference receivers. These differential corrections are valid as long as the ionospheric delay is homogeneous in space. Since the ionosphere is spatially variable, however, differential correction errors associated with spatial decorrelation of the ionospheric delay, or in other words ionospheric spatial gradients, must be considered and mitigated.

In GBAS, normally occurring gradients in ionospheric delay, commonly termed "nominal ionospheric gradients," are mitigated by determining a conservative one-sigma parameter $\left(\sigma_{\text {vig }}\right)$ (ICAO 2014) to bound the uncertainty in the nominal vertical ionospheric delay gradient. This parameter is of the order of several millimeters per kilometer at the GPS L1 frequency (Lee et al. 2007). This value is broadcast by GBAS ground systems and is an input to aircraft calculation of protection levels, which bound errors in the position-domain (Rife and Pullen 2007). When these protection levels exceed the alert limits, which are the designated safe limits, the GBAS service becomes unavailable.

However, it is known that ionospheric delay may greatly deviate from nominal levels due to various disturbances (Mendillo 2006). For example, enhancements in ionospheric TEC associated with strong geomagnetic storms (Foster et al. 2002) may result in slant ionospheric delay gradients of more than $400 \mathrm{~mm} / \mathrm{km}$ (Pullen et al. 2009) or approximately 100 times the typical value of $\sigma_{\text {vig. }}$. If differential correction errors associated with such anomalous ionospheric delay gradients were to be bounded by the protection levels, they would almost always exceed the alert limit, and the GBAS service would be unavailable to airspace users. Therefore, anomalous ionospheric delay gradients are usually treated separately from nominal ionospheric delay gradients. To the extent possible, they are detected, and the affected satellites are excluded by integrity monitors deployed in the GBAS ground and airborne subsystems. Anomalous gradients that cannot be detected to the required integrity probability must be mitigated by separately limiting the aircraft satellite geometry to ensure that aircraft potentially exposed to such gradients do not experience unsafe position errors. This latter approach is known as "geometry screening" (Seo et al. 2012).

To design the integrity monitors relevant to the ionospheric delay gradient and therefore ensure that an acceptable level of safety is reached, characteristics of ionospheric delay gradients must be defined. In GBAS, an ionospheric delay gradient is usually approximated by an infinitely long front. The range of ionospheric delay gradients possible over a given region is referred to as the "ionospheric threat model." It should be noted that the ionospheric threat model used for civil aviation has to be sufficiently protective but should not be too conservative because systems used for civil aviation must be safe and at the same time sufficiently available for approach and landing operations.

It is common to define the ionospheric threat model in terms of slant ionospheric delay gradient, i.e., without conversion from a slant to vertical delays. The ionospheric threat model is defined to bound worst-case ionospheric delay gradients. However, it is difficult to estimate the occurrence probability of extremely large ionospheric delay gradients that occur very infrequently. The lack of a large database of observed extreme gradients makes it impractical to derive an upper bound on gradient magnitude by normal statistical methods. Instead, the upper bound of the ionospheric threat model is selected to exceed any ionospheric delay gradients that have ever been observed in an area of interest.

For example, ICAO has defined a reference ionospheric threat model to be used in the validation of new standards and the verification of new GBAS equipment enabling Category-II/III approach and landing (ICAO Navigation Systems Panel, GBAS CAT II/III Development Baseline SARPs.). Since ionospheric conditions vary with magnetic latitude, the USA has defined its own ionospheric threat model applicable over the Conterminous US (CONUS) for Category-I GBAS (Pullen et al. 2009). Similar studies have 
also been conducted in Australia (Terkildsen 2010), South Korea (Kim et al. 2014), Germany (Mayer et al. 2009), and more widely over Europe (Schlüter et al. 2013). These studies are based on observations in the magnetic midlatitude region, where strong ionospheric disturbances that may impact GBAS do not frequently occur. The studies conducted for these mid-latitude regions show that all ionospheric delay gradients fall well within the bounds of the GBAS Category-I ionospheric threat model for CONUS. On the other hand, in the low magnetic latitude region where ionospheric disturbances regularly occur, as discussed in the next subsection, only a few studies have been conducted (Saito et al. 2012a; Rungraengwajiake et al. 2015; Lee et al. 2015).

\section{Low-latitude ionospheric disturbances}

As noted above, the ionosphere behaves differently at different magnetic latitudes. The low-magnetic latitude ionosphere may be defined as the ionosphere that is affected by the equatorial plasma fountain, which generates the equatorial ionization anomaly (EIA) crests at around $\pm 15^{\circ}$ magnetic latitude. It is characterized by various ionospheric disturbances unique to the region (Kelley 2008). Among them, plasma bubbles are known as the most dynamic ionospheric disturbance in the region. Plasma bubbles are regions of low ionospheric plasma density that develop over the magnetic equator and rise vertically as high as $1000 \mathrm{~km}$ or more, somewhat like a "bubble" in water (Woodman and LaHoz 1976). The eastwest and north-south cross sections of a plasma bubble are illustrated in the left panels of Fig. 1. As a bubble rises higher, it expands in the poleward direction along the earth's magnetic field lines. The typical longitudinal width is about $100 \mathrm{~km}$, and the typical latitudinal extent can be up to several thousands of $\mathrm{km}$. Since the boundary between the outside and inside of a plasma bubble is very narrow,

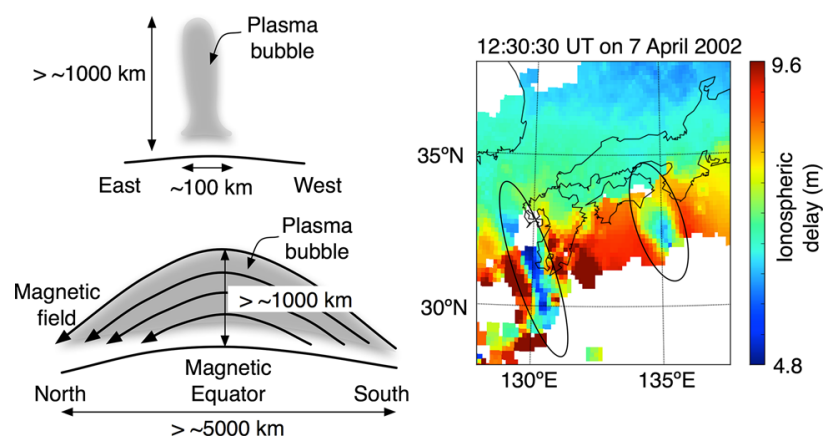

Fig. 1 General features of plasma bubbles. Left cross sections of plasma bubble in a zonal-vertical plane over the magnetic equator (top) and in a meridional-vertical plane (bottom) are illustrated. Right an example of plasma bubbles seen on an ionospheric delay map is also shown. Two ovals indicate plasma bubbles

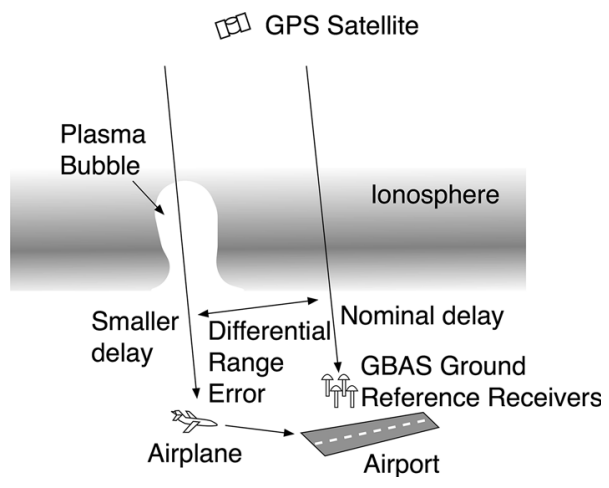

Fig. 2 Plasma bubble and differential range error in GBAS

the ionospheric delay on nearby satellite-receiver paths may vary drastically depending on whether they pass inside or outside the bubble. Therefore, a plasma bubble may be observed as a sharp drop or recovery in ionospheric delay, as shown in Fig. 1 (right), and can generate a large ionospheric delay gradient that may impact GBAS, as illustrated in Fig. 2.

It is important to note that the characteristics of plasma bubbles are very different from the characteristics of midlatitude ionospheric disturbances. The physical mechanism of plasma bubbles, the Rayleigh-Taylor plasma instability (Dungey 1956) is very different from those of mid-latitude ionospheric disturbances. Plasma bubbles occur much more frequently than mid-latitude ionospheric disturbances of sufficient magnitude to impact GBAS. The seasonal and local time variation of plasma bubble occurrences is also very different. Plasma bubbles occur almost every day, potentially anytime between dusk and dawn, in certain seasons (Burke et al. 2004). Therefore, the characteristics of plasma bubbles and their impact on GBAS must be assessed separately from those of mid-latitude disturbances.

\section{ICAO APAC ionospheric studies task force (ISTF)}

With the increasing demand for GNSS implementation for air navigation, the ICAO Asia-Pacific Air Navigation Planning and Implementation Regional Group (APANPIRG) recognized the need to assess regional ionospheric characteristics and their potential impact on GNSS in 2010. Some States/Administrations in the ICAO APAC region are situated in the low-magnetic latitude region where the ionospheric characteristics are different from those in the mid-latitude region and have not been as thoroughly studied. In the region spanning longitudes $60^{\circ} \mathrm{E}$ to $120^{\circ} \mathrm{W}$ that includes most of Asia and the Pacific Ocean, the characteristics of ionospheric disturbances in the lowmagnetic latitudes can be regarded as similar (Burke et al. 2004). 
Recognizing the need to mitigate the ionospheric threat, the Communication, Navigation, and Surveillance (CNS) subgroup of ICAO APANPIRG decided to assess the ionospheric characteristics in their region in an internationally coordinated manner. Thus, the ionospheric studies task force (ISTF) was established in 2011 by the CNS subgroup to facilitate ionospheric data collection, sharing, and analysis. The ISTF was also tasked to develop regional ionospheric threat models for GBAS and SBAS. The latest terms of reference of the ISTF are published by the ICAO APAC Office [International Civil Aviation Organization Asia Pacific Office, Revised terms of reference of ISTF. Attachment A to the report of the third meeting of ionospheric studies task force (ISTF/3)]. GNSS measurement data were collected and shared by the contributing States/ Administrations. Subject matter experts from the member States/Administrations shared and analyzed the data cooperatively. Cooperation among multiple states to analyze ionospheric delay gradient data across the low-latitude Asia-Pacific region and provide a single reference model for GBAS implementation in the region is novel from both a scientific and engineering point of view.

\section{Scope}

The objective of this study is to present the results of an ionospheric threat assessment for GBAS in the Asia-Pacific region by the ICAO APAC ISTF based on data contributed by a number of States/Administrations and regional organizations and analyzed by ISTF members. The methods used to analyze the collected data are explained in the next section. A section to introduce the data used in this study follows. Finally, results of the analysis are presented and discussed.

\section{Methodology}

Two tools are used to analyze collected GPS data, find examples of anomalous ionospheric behavior, and derive estimates of ionospheric delay gradients. One is the longterm ionosphere anomaly monitoring (LTIAM) software package developed by the US Federal Aviation Administration (FAA) and the Korea Advanced Institute of Science and Technology (KAIST), South Korea (Jung and Lee 2012). LTIAM was developed for the purpose of continually evaluating the validity of the existing CONUS threat model and updating it if gradients not bounded by the model are discovered in future observations. LTIAM software implements a simplified and automated algorithm to estimate precise slant ionospheric delays using dual-frequency (L1 and L2) GNSS measurements at all available pairs of GNSS receivers. The delay difference between a pair of receivers tracking a GNSS satellite is divided by the baseline distance between those receivers to give an estimate of the ionospheric delay gradient. Additionally, LTIAM estimates the ionospheric delay gradient based on the difference between the code and carrier-phase measurements (code-minus-carrier, or CMC) of the L1 signal.

LTIAM automatically selects and outputs measurement pairs that have large estimated ionospheric delay gradients. These candidates are manually verified by visual inspection, including comparisons between dual-frequency and L1 CMC gradient estimates, to confirm that the observed gradients are due to ionospheric behavior as opposed to receiver faults or post-processing errors such as undetected cycle slips in carrier-phase measurements or code-carrier leveling uncertainty. This is necessary because those errors can generate large apparent ionospheric gradients which are not real. Candidates which are not verified manually are discarded, as they are not reliable. LTIAM is a robust tool for processing a large amount of data in a reasonable amount of time.

The other tool is the single-frequency carrier-based and code-aided technique (SF-CBCA) developed by the Electronic Navigation Research Institute, Japan (Fujita et al. 2010; Saito et al. 2012b). SF-CBCA uses single-frequency carrierphase and code measurements to estimate ionospheric delay differences between a pair of GNSS receivers. The process includes ambiguity resolution of carrier-phase differences. Since it is based on single-frequency measurements, it is free from ionospheric delay difference estimation error caused by inter-frequency bias, which is difficult to calibrate perfectly in dual-frequency measurements. On the other hand, errors associated with ephemeris errors become larger as the distance between a pair of GNSS receivers becomes longer. Therefore, SF-CBCA is suitable for receiver pairs with relatively short baselines of as much as $10 \mathrm{~km}$, though very precise relative positions of the receivers are needed. In addition, by using three GNSS receivers, which give three unique combinations of two GNSS receivers, the validity of the solutions can be checked by taking the cyclic sum of the ionospheric delay differences from the three pairs (Saito et al. $2012 b$ ). With the cyclic sum check, the worst-case error of gradient estimation can be limited at most to the ionospheric delay equivalent to a half wavelength of the L1 signal divided by the distance between stations.

These two methods have been shown to produce equivalent results. LTIAM is based on the ionospheric delay values derived from dual-frequency measurements. Thus, the derivation of ionospheric delay gradients by LTIAM is straightforward. The equivalency of the ionospheric delay gradients estimated by SF-CBCA and by the dual-frequency method is demonstrated by Saito and Yoshihara (2017).

In this study, both methods (LTIAM and SF-CBCA) have been used. Which method was used to analyze a particular data set depended on the details of that data set, 
such as the distances between receivers, the availability of very precise station locations, and the computing environment of the analyzing center. In LTIAM analysis, a satellite elevation mask of $10^{\circ}$ was applied, because L1 CMC validation is difficult at lower elevation angles due to multipath noise in code measurements. An elevation mask of $0^{\circ}$ was used in SF-CBCA analysis.

\section{Data analyzed}

The data used in this study was collected and shared by the member States/Administrations and regional organizations in the ICAO APAC region. Table 1 summarizes the locations of data sources, and corresponding data periods, and the analysis method used for each set of data. Data from Hong Kong, Hyderabad, and Bangalore were collected in periods covering a whole solar cycle. Data from other locations also collected around the last solar maximum period, which occurred in 2011. Figure 3 shows the geographic distribution of the data sources. It can be seen that the data sources are widely distributed over the region of interest, both in longitude from $78^{\circ} \mathrm{E}$ to $124^{\circ} \mathrm{E}$ and in latitude from $7^{\circ} \mathrm{S}$ to $24^{\circ} \mathrm{N}$ ( -17 to $+20^{\circ}$ in magnetic latitude).

\section{Results and discussion}

In the following, all the ionospheric delay gradients are discussed with regard to the L1 frequency, with units of millimeters of delay per kilometer of baseline, because

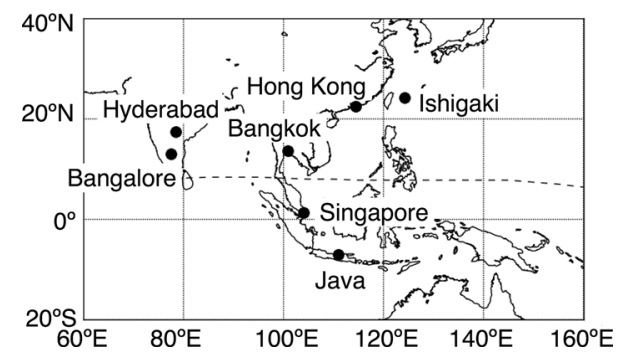

Fig. 3 Locations where the ionospheric delay gradients are analyzed. Dashed line shows the magnetic equator

current GBAS is defined purely for single-frequency L1 GNSS signals.

Figure 4 shows an example of ionospheric delay gradient analysis results using LTIAM for data recorded in Singapore. This example shows the largest gradient observed in Singapore. It was observed on GPS PRN 32 satellite on March 26, 2012, and it represents the largest gradient derived by LTIAM over the set of data collected and analyzed by ISTF. Geomagnetic activity was quiet during the period of observation $\left(K_{\mathrm{p}} \leq 1+\right)$ (World Data Center for Geomagnetism, Kyoto, http://wdc.kugi.kyoto-u. ac.jp). Figure 4 (top, left) shows the ionospheric delay values of the two receivers (SNYP and SLOY, which are separated by about $13.7 \mathrm{~km}$ in a roughly west-to-east direction) over several hours in the late afternoon and evening. The local time at $104^{\circ} \mathrm{E}$ is $6.9 \mathrm{~h}$ ahead of UT. A strong plasma bubble of ionospheric delay depletion first affected SNYP at around 13.5 UT and moved eastward to affect SLOY a few minutes later. Figure 4 (top, right) shows the resulting ionospheric delay gradient estimates

Table 1 Data used for analysis

\begin{tabular}{|c|c|c|c|}
\hline $\begin{array}{l}\text { Location } \\
\text { (Lat., Lon., Magnetic. Lat.) }\end{array}$ & Period & Analysis method & Baseline length $(\mathrm{km})$ \\
\hline $\begin{array}{l}\text { Hong Kong } \\
\left(22.5^{\circ} \mathrm{N}, 114.4^{\circ} \mathrm{E},+14.6^{\circ}\right)\end{array}$ & Oct. 2000-Sep. 2013 & LTIAM & $4.8-21$ \\
\hline $\begin{array}{l}\text { Hyderabad, India } \\
\left(17.4^{\circ} \mathrm{N}, 78.5^{\circ} \mathrm{E},+12.9^{\circ}\right)\end{array}$ & 2004-2015 & LTIAM & 9.3 \\
\hline $\begin{array}{l}\text { Bangalore, India } \\
\left(13.0^{\circ} \mathrm{N}, 77.5^{\circ} \mathrm{E},+7.6^{\circ}\right)\end{array}$ & 2004-2015 & LTIAM & $6-20$ \\
\hline $\begin{array}{l}\text { Java, Indonesia } \\
\left(7^{\circ} \mathrm{N}, 106-114^{\circ} \mathrm{E},-16^{\circ}\right)\end{array}$ & 2013-2015 & LTIAM & $15-84$ \\
\hline $\begin{array}{l}\text { Ishigaki, Japan } \\
\left(24.3^{\circ} \mathrm{N}, 124.2^{\circ} \mathrm{E},+19.6^{\circ}\right)\end{array}$ & $\begin{array}{l}\text { Mar.-Apr. } 2008 \\
\text { Sep.-Oct. } 2010\end{array}$ & SF-CBCA & 1.4 \\
\hline $\begin{array}{l}\text { Singapore } \\
\left(1.3^{\circ} \mathrm{N}, 104.0^{\circ} \mathrm{E},-6.8^{\circ}\right)\end{array}$ & $\begin{array}{l}\text { Sep.-Nov. } 2011 \\
\text { Mar.-Apr., Sep.-Oct. } 2012 \\
\text { Mar.-May, Sep.-Nov. } 2013 \\
\text { Feb.-Apr., Sep.-Oct. } 2014 \\
\text { Mar.-Jul. } 2016\end{array}$ & LTIAM & $2.3-33$ \\
\hline $\begin{array}{l}\text { Bangkok, Thailand } \\
\left(13.7^{\circ} \mathrm{N}, 100.8^{\circ} \mathrm{E},+8.0^{\circ}\right)\end{array}$ & Sep.-Oct. 2011 & SF-CBCA & 12 \\
\hline
\end{tabular}



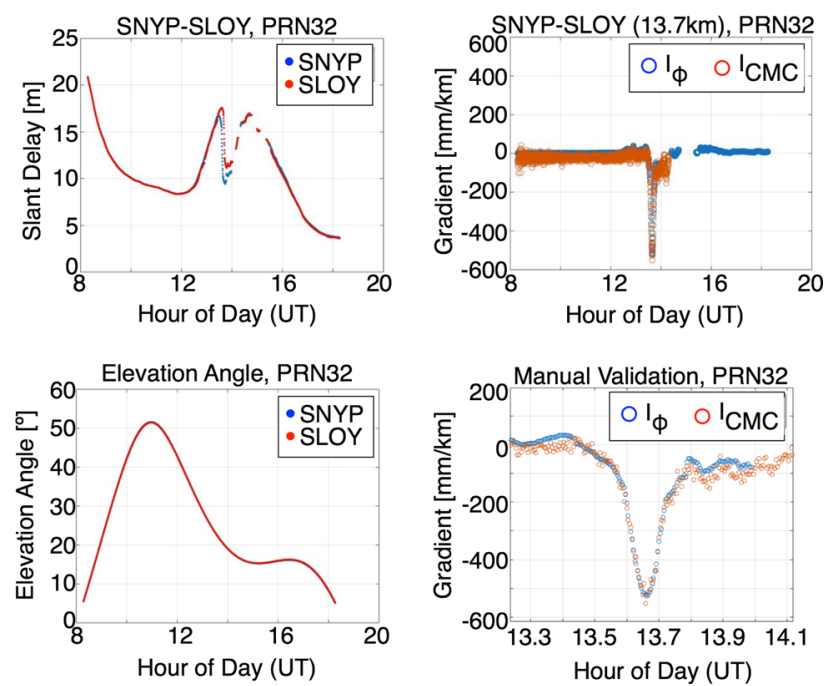

Fig. 4 Largest gradient event observed at Singapore on March 26, 2012. Dual-frequency ionospheric delays observed by the two receivers for the GPS PRN 32 satellite (top-left), gradient (top-right), satellite elevation angle (bottom-left), and close-up of gradients estimated by dual-frequency and CMC measurements (bottom-right) are shown

derived from both dual-frequency and CMC measurements. Figure 4 (bottom, right) shows the close-up of Fig. 4 (top, right) from 13.25 to 14.11 UT. The maximum gradient of about $505.2 \mathrm{~mm} / \mathrm{km}$ occurred at about 1340 UT, after SNYP had experienced almost all of the depletion while SLOY was just beginning to be affected and thus observed a much higher delay. Figure 4 (top, right) also shows that both dual-frequency and CMC estimates of gradient over time agree closely, which helps validate that erroneous receiver measurements did not create this event. As shown in Fig. 4 (bottom, left), this large gradient was observed at a relatively low-elevation angle of $\left(21.05^{\circ}\right)$.

Figure 5 shows another example of LTIAM ionospheric delay gradient analysis results. This example shows the largest gradient observed in Hong Kong, China, which occurred on the GPS PRN 07 satellite on April 11, 2013. It was the second largest gradient derived by LTIAM. The geomagnetic activity was quiet $\left(K_{\mathrm{p}} \leq 2\right)$. The distance between the two receivers of HKSS and HKWS that made these observations of PRN 07 is $6.81 \mathrm{~km}$. As shown in the top panels of Fig. 5, there were two disturbances around 14.25 and $16.3 \mathrm{UT}\left(\mathrm{LT}=\mathrm{UT}+7.6 \mathrm{~h}\right.$ at $\left.114^{\circ} \mathrm{E}\right)$. Figure 5 (bottom, right) shows the close-up of Fig. 5 (top, right) from 16.0 to 16.55 UT. From 16.37 UT, the gradient estimated by L1 CMC starts to drop from $+21.3 \mathrm{~mm} / \mathrm{km}$ continuously to $-456.4 \mathrm{~mm} / \mathrm{km}$. The gradient obtained from dual-frequency measurements followed the gradient estimated from CMC until it jumped back to about $-100 \mathrm{~mm} / \mathrm{km}$, which was apparently due to cycle slips in carrier-phase measurements. In this case, the real largest
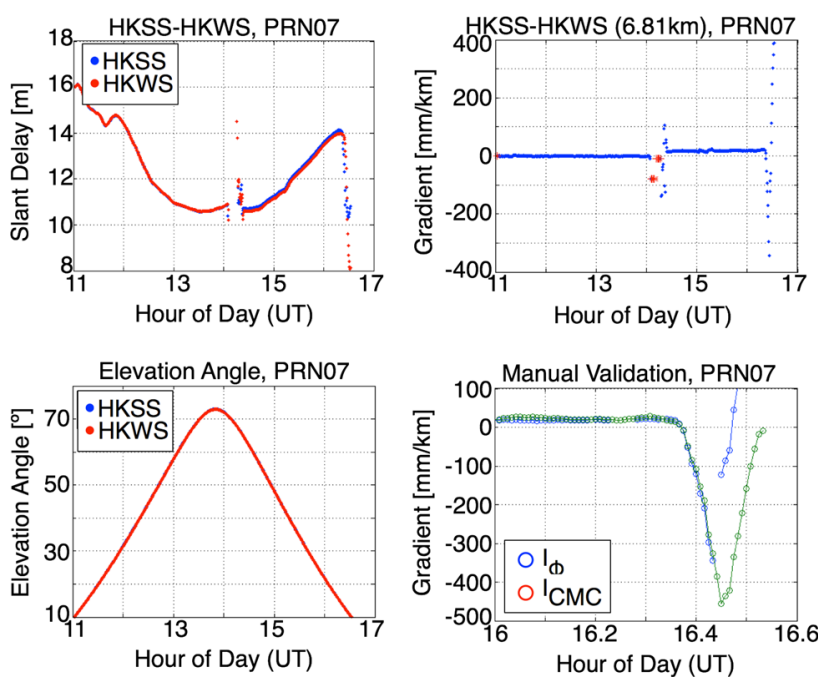

Fig. 5 Same as Fig. 4, but is plotted for the largest gradient event observed at Hong Kong China on April 11, 2013, for the GPS PRN 07 satellite

gradient is estimated as $-477.7 \mathrm{~mm} / \mathrm{km}$ from the CMC measurements by taking the constant gradient of $+21.3 \mathrm{~mm} / \mathrm{km}$ that occurred before the disturbance as the reference level. As shown in Fig. 5c, this gradient was observed at a very low-elevation angle $\left(11.75^{\circ}\right)$.

Figure 6 shows an example of ionospheric delay gradient analysis results by SF-CBCA for data recorded in Ishigaki, Japan, which is south of the Japanese home islands and is about $250 \mathrm{~km}$ east of Taiwan. Figure 6 (top) shows ionospheric delay observed at Ishigaki on the GPS PRN 22 satellite on April 3, 2008. The magnetic activity on the day was very quiet $\left(K_{\mathrm{p}} \leq 1\right)$. It can be seen that
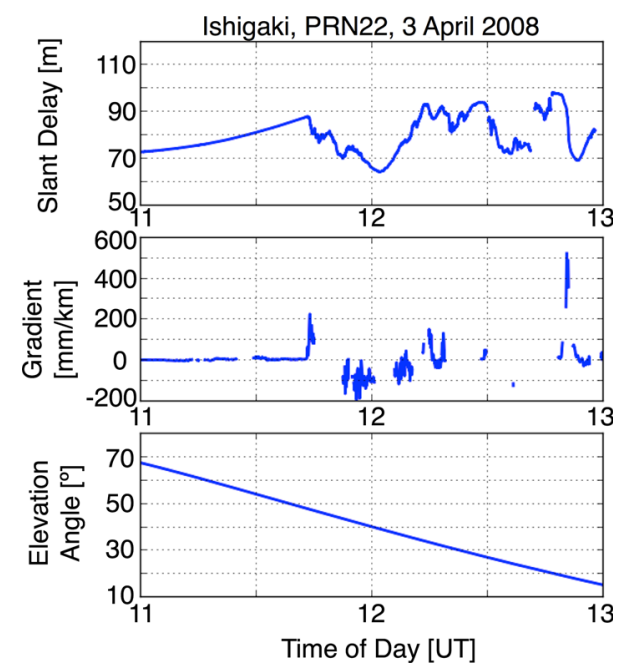

Fig. 6 Largest gradient observed at Ishigaki, Japan on April 3, 2008. Dual-frequency ionospheric delay observed by one of the receivers for the GPS PRN 22 satellite (top), gradient (middle), satellite elevation angle (bottom) are shown 
multiple plasma bubbles (i.e., multiple drops in ionospheric delay) passed over Ishigaki. Figure 6 (middle) shows the ionospheric delay gradients for the same period observed by a receiver pair separated by $1.37 \mathrm{~km}$ in a roughly eastto-west direction. The largest gradient of $518 \mathrm{~mm} / \mathrm{km}$ was observed at $12.48 \mathrm{UT}\left(\mathrm{LT}=\mathrm{UT}+8.3 \mathrm{~h}\right.$ at $\left.124.2^{\circ} \mathrm{E}\right)$ corresponding to the sharp drop in ionospheric delay at the same time. At Ishigaki, there are five GNSS receivers (Saito et al. 2012a). The gradient values are validated by checking the consistency with gradients measured by other nearby receiver pairs. As shown in Fig. 6 (bottom), the largest gradient was observed at a relatively low-elevation angle $\left(18.45^{\circ}\right)$.

In contrast to these events with large gradients observed at low-elevation angles, a relatively large gradient was observed at a high-elevation angle $\left(77^{\circ}\right)$ at Hyderabad, India. Though it was not the largest gradient observed at Hyderabad, it is worthwhile to show this example due to its combination of high gradient and high elevation angle. Figure 7 shows the results of the analysis of this example as derived by LTIAM. It was observed on March 1, 2015, on the GPS PRN 06 satellite. The magnetic activity on this day was moderate $\left(K_{\mathrm{p}} \leq 5+\right)$, but it was quiet when these plasma bubbles were observed $\left(K_{\mathrm{p}} \leq 3-\right)$. Multiple plasma bubbles, some small and some large, were observed from about 16.0 to $19.0 \mathrm{UT}\left(\mathrm{LT}=\mathrm{UT}+5.2 \mathrm{~h}\right.$ at $\left.78.5^{\circ} \mathrm{E}\right)$. At around 18.3 UT, sharp drops in the ionospheric delay were observed, as shown in Fig. 7 (top, left). Associated with these sharp drops, the estimated gradient continuously increased to $+308 \mathrm{~mm} / \mathrm{km}$ from $-51 \mathrm{~mm} / \mathrm{km}$ for a receiver pair (HYDE and HYDR) separated by $9.28 \mathrm{~km}$, as shown in the right panels of Fig. 7. The continuous behavior of the gradient derived by dual-frequency
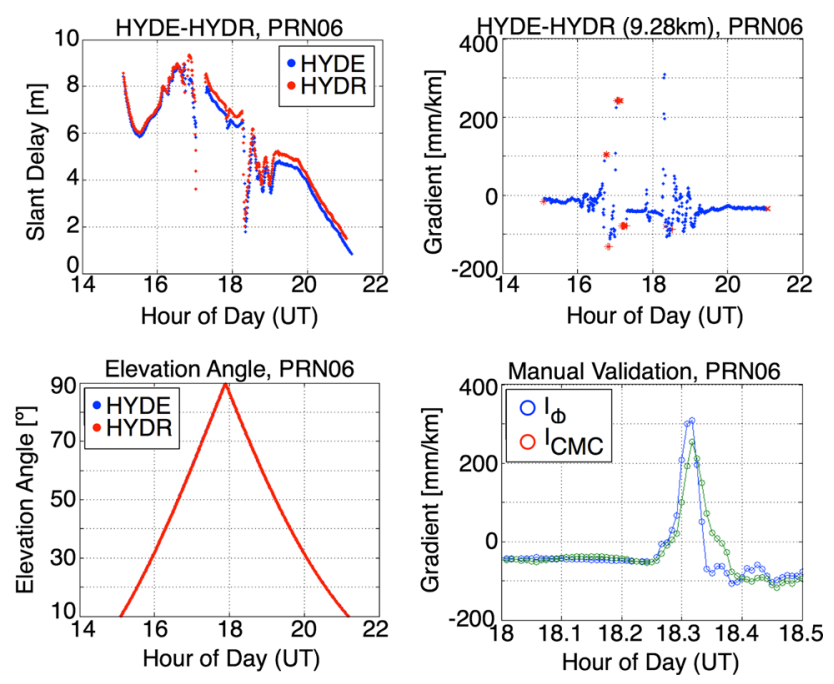

Fig. 7 Same as Fig. 5, but is plotted for the large gradient event at a high-elevation angle $\left(77^{\circ}\right)$ at Hyderabad, India on March 1, 2015, for the GPS PRN 06 satellite measurements, and its consistency with that derived by L1 CMC measurements, indicates that the gradient is likely to be real. As shown in Fig. 7 (bottom, left), the elevation angle of the GPS PRN 06 satellite was quite high $\left(77^{\circ}\right)$.

Figure 8 shows all of the ionospheric delay gradients larger than $100 \mathrm{~mm} / \mathrm{km}$ obtained from the data listed in Table 1 as a function of satellite elevation angle. From Ishigaki and Bangkok data analyzed by SF-CBCA, no validated gradient data was obtained at elevation angles below $10^{\circ}$. From other data analyzed by LTIAM, no gradient data was obtained at elevation angles below $10^{\circ}$, because dual-frequency data at low elevation angles are very noisy, and satellites below an elevation angle of $10^{\circ}$ were not used. Therefore, there are no data points at elevation angles below $10^{\circ}$ in the figure. Nevertheless, according to previous studies in other regions (Pullen et al. 2009; Terkildsen 2010; Kim et al. 2014; Lee et al. 2015), there is no evidence that gradients in the elevation range of $5^{\circ}-10^{\circ}$ are significantly larger than gradients at an elevation angle of $10^{\circ}$. Weak elevation angle dependence, i.e., increasing ionospheric gradient with decreasing elevation angle, can be seen in the figure as well as in these previous studies. However, because little data below $10^{\circ}$ is present, the extension of the maximum gradient in the threat model below $10^{\circ}$ must be regarded as speculative at the current time.

An example of functions that give physically significant elevation angle dependence is the slant factor function, which gives the relationship between slant and vertical ionospheric delays with an assumption of a thin ionospheric shell at a fixed altitude (thin-shell model).

$g(\mathrm{El})=S(\mathrm{El}) \cdot g_{0}[\mathrm{~mm} / \mathrm{km}]$

where $g_{0}$ is the vertical ionospheric delay gradient. $S(\mathrm{El})$ is the slant factor as a function of the elevation angle (El) with an assumed ionospheric shell height of $350 \mathrm{~km}$ (ICAO 2014) and is given by:

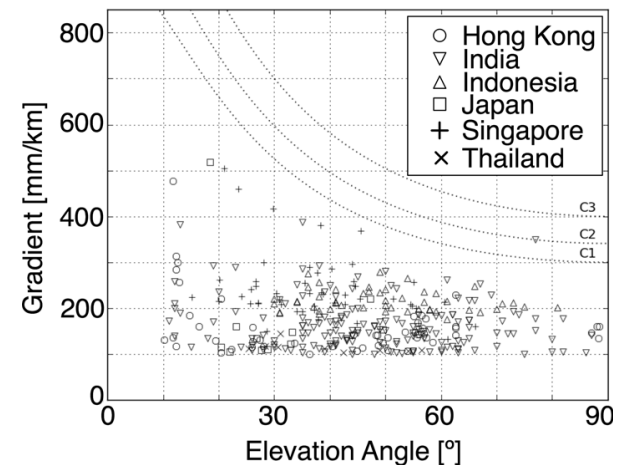

Fig. 8 Ionospheric gradients larger than $100 \mathrm{~mm} / \mathrm{km}$ as a function of the elevation angle. Different signs indicate different locations where the gradients are observed. Dotted lines show the gradients following Eq. (1) with the vertical gradient values in Table 2 


$$
S(\mathrm{El})=\frac{1}{\sqrt{1-\left(\frac{R_{\mathrm{e}} \cos \mathrm{El}}{R_{\mathrm{e}}+350}\right)^{2}}}
$$

where $R_{\mathrm{e}}$ is the radius of the earth at the equator $(6378.14 \mathrm{~km})$.

The dotted curves in Fig. 8 show the gradient calculated by (1) with different equivalent vertical gradient values summarized in Table 2. Most of the largest gradients obtained in this study (i.e., those above $300 \mathrm{~mm} / \mathrm{km}$ ) follow the shape of these slant factor functions. Curve $\mathrm{C} 1$ closely fits the envelope of the gradient distribution except for the single event of $349 \mathrm{~mm} / \mathrm{km}$ at $77^{\circ}$ from Hyderabad, which is not bounded. Unbounded events like this are of concern for the development of an ionospheric threat model for use in civil aviation because of the demanding $\left(1-10^{-7 \sim-9}\right)$ integrity requirements and because only a limited number of anomalous gradient observations are available. Curve $\mathrm{C} 2$ is chosen so that it passes through the data point of $349 \mathrm{~mm} / \mathrm{km}$ at $77^{\circ}$. Curve C3 is chosen to bound all the gradients with a certain margin. All these curves, however, appear to be too conservative at lowelevation angles, with values at the lowest elevation angles more than twice the maximum observed gradient, although data at elevation angles below $10^{\circ}$ is limited. Too much conservatism should be avoided in civil aviation, because it would degrade the availability of the system, as pointed out earlier. Therefore, the threat model needs to be defined considering the balance between safety margin and availability.

In Fig. 9 and Table 3, three options for the ionospheric threat model are presented. The solid line is the first option, in which the upper bound on the ionospheric delay gradient is constant at $600 \mathrm{~mm} / \mathrm{km}$ for all elevation angles. The $600 \mathrm{~mm} / \mathrm{km}$ value is chosen so that all the observed gradients are well bounded. This value exceeds the largest gradient values in the data set by about $15 \%$. This $15 \%$ margin is considered to be sufficient to bound the measurement and analysis errors. Moreover, the data set includes data for one solar cycle (11 years) at three locations, which are Hong Kong, Hyderabad, and Bangalore, plus data from other locations. Considering that the exposure time of the most critical phase of precision approach as $15 \mathrm{~s}$ (ICAO 2014), three times 11 years, which is $1.04 \times 10^{9} \mathrm{~s}$, is equivalent to $7 \times 10^{7} 15$-s samples, which approaches the integrity level required for Category-I approach $\left(1-10^{-7}\right)$. Therefore, a bound of $600 \mathrm{~mm} / \mathrm{km}$ value on gradients in the APAC region has significant

Table 2 Equivalent vertical gradients for curves in Fig. 8

\begin{tabular}{llll}
\hline & $\mathrm{C} 1$ & $\mathrm{C} 2$ & $\mathrm{C} 3$ \\
\hline$g_{\mathrm{o}}$ & 300 & 341 & 400 \\
\hline
\end{tabular}

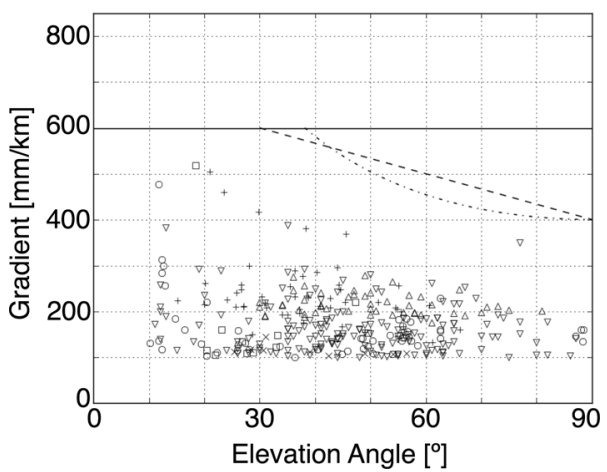

Fig. 9 Same as Fig. 8. The symbols indicate locations where the gradients were observed as shown in Fig. 8. Horizontal solid line is drawn at $600 \mathrm{~mm} / \mathrm{km}$ (Option 1 in Table 3). Dashed and dash-doted lines show the Options 2 and 3, respectively, in Table 3

Table 3 Options of ionospheric threat model

\begin{tabular}{ll}
\hline Option 1 & $600\left(5^{\circ} \leq \mathrm{El} \leq 90^{\circ}\right)$ \\
Option 2 & $600\left(5^{\circ} \leq \mathrm{El} \leq 30^{\circ}\right), 700-(10 / 3) \cdot \mathrm{El}\left(30^{\circ}<\mathrm{El} \leq 90^{\circ}\right)$ \\
Option 3 & $600\left(5^{\circ} \leq \mathrm{El} \leq 38.16^{\circ}\right), 400 \cdot S(\mathrm{El})\left(38.16^{\circ}<\mathrm{El} \leq 90^{\circ}\right)$ \\
\hline
\end{tabular}

statistical weight when applied to Category-I approach. For Category-II/III approach and landing that require integrity level of $1-10^{-9}$, more data and analysis are likely to be needed. In fact, because of the rarity of extreme ionospheric events, continued monitoring of ionospheric gradients is recommended to support Category-I, II, and III approaches to detect any future events that might exceed the bounds of this threat model.

As noted above, a constant bound of $600 \mathrm{~mm} / \mathrm{km}$ is reasonably larger than the largest gradients derived by LTIAM $(505.2 \mathrm{~mm} / \mathrm{km})$ and SF-CBCA $(518 \mathrm{~mm} / \mathrm{km})$ plus the maximum potential measurement errors for each event (19.5 and $65.7 \mathrm{~mm} / \mathrm{km}$, respectively). The dashed line is the second option, in which the upper bound is constant at $600 \mathrm{~mm} / \mathrm{km}$ at elevation angles from $5^{\circ}$ to $30^{\circ}$ and then linearly decreases to $400 \mathrm{~mm} / \mathrm{km}$ at $90^{\circ}$. The dash-dotted line is the third option, in which the upper bound is constant at $600 \mathrm{~mm} / \mathrm{km}$ at elevation angles from $5^{\circ}$ to $38.16^{\circ}$ and then decreases to $400 \mathrm{~mm} / \mathrm{km}$ at $90^{\circ}$ using the definition of $\mathrm{S}(\mathrm{El})$ given in (2). The high-elevation part of Option 3 is the same as Curve C3 in Fig. 8. All three options completely bound all observed data points.

The next question is which option should be adopted. Both Options 2 and 3 are less conservative than Option 1 at higher-elevation angles. However, there is no clear physical basis for having a linear decrease, as in Option 2. Option 3 has some physical basis and is the least conservative among the three options at higher-elevation angles.

Because the number of available samples of large gradients at high-elevation angles is limited, it is most reasonable to adopt Option 1, which is a constant upper bound 
of $600 \mathrm{~mm} / \mathrm{km}$ for all elevation angles. When more gradient samples are obtained in the future and more confidence gained in the statistics, the conservative margin that Option 1 provides at higher-elevation angles may be reduced.

Note that while Options 1,2 , or 3 in Table 3 are meant to extend down to a minimum elevation angle of $5^{\circ}$, the lack of observations below $10^{\circ}$ means that use of this threat model below $10^{\circ}$ is speculative and is based on engineering judgment and experience with previous observations of ionospheric anomalies. Further analysis by SF-CBCA, which is more robust against the disturbances that affect low-elevation measurements, may provide observations below $10^{\circ}$ from the existing data set and provide more confidence on the gradient bound in the elevation angle range between $5^{\circ}$ and $10^{\circ}$.

The upper bound of $600 \mathrm{~mm} / \mathrm{km}$ on the ionospheric delay gradient in this model is higher than those in similar threat models established for mid-latitude regions (Pullen et al. 2009; Mayer et al. 2009; Terkildsen 2010; Schlüter et al. 2013), which have bounds as large as $425 \mathrm{~mm} / \mathrm{km}$. It is also higher than those found in previous studies of the Asia-Pacific region (Kim et al. 2014; Rungraengwajiake et al. 2015). However, it is lower than the largest gradient found in Brazil $(850 \mathrm{~mm} / \mathrm{km})$ (Lee et al. 2015), which is also in the low-latitude region. This longitudinal difference across the low-latitude region may be real or may be due to the limited observations of large gradients conducted to date. Further study is needed to understand this difference better, if it exists, and its physical basis.

\section{Conclusion}

GPS observation data obtained in the Asia-Pacific region was analyzed for anomalous ionospheric delay gradients to develop a regional ionospheric threat model for GBAS. The largest gradient value in the analyzed data was $518 \mathrm{~mm} / \mathrm{km}$ at Ishigaki, Japan, while gradients almost this large were also observed at Hong Kong and Singapore. Most of the observed gradients above $300 \mathrm{~mm} / \mathrm{km}$ appear to have an elevation angle dependence that is similar to the slant factor function. However, the slant factor function cannot bound all the gradients without being too conservative.

Therefore, the upper bound of the ionospheric delay gradient was chosen to be constant at $600 \mathrm{~mm} / \mathrm{km}$ without any elevation angle dependence for the proposed GBAS ionospheric threat model for the ICAO Asia-Pacific region. More data analysis is desirable to demonstrate that this model continues to bound future gradients and to support Category-II/III approach and landing. It is hoped that future data analysis will provide a stronger justification to reduce the gradient bound at higher elevation angles. Furthermore, it would be desirable to obtain low-noise data at elevation angles below $10^{\circ}$ to provide additional support for using the threat model down to $5^{\circ}$, as is currently done in GBAS.

Acknowledgements The data sets used in the work of ISTF have been contributed by the Asia-Pacific Economic Cooperation, GNSS Implementation team; Australia; Hong Kong, China; India; Badan Informasi Geospasial (BIG), Indonesia; National Mapping and Resource Information Authority (NAMRIA), Philippines; Civil Aviation Authority of Singapore (CAAS); and Thailand.

Open Access This article is distributed under the terms of the Creative Commons Attribution 4.0 International License (http://crea tivecommons.org/licenses/by/4.0/), which permits unrestricted use, distribution, and reproduction in any medium, provided you give appropriate credit to the original author(s) and the source, provide a link to the Creative Commons license, and indicate if changes were made.

\section{References}

Burke WJ, Huang CY, Gentile LC, Bauer L (2004) Seasonallongitudinal variability of equatorial plasma bubbles. Ann Geophys 22(8):3089-3098, SRef-ID: 1432-0576/ag/2004-223089

Dungey JW (1956) Convective diffusion in the equatorial F-region. J Atmos Terr Phys 9(5):304-310

EUROCAE ED-114A (2013) MOPS for global navigation satellite ground based augmentation system ground equipment to support category I operations

Foster JC, Erickson PJ, Coster AJ, Goldstein J, Rich FJ (2002) Ionospheric signatures of plasmaspheric tails. Geophys Res Lett. doi:10.1029/2002GL015067

Fujita S, Yoshihara T, Saito S (2010) Determination of ionospheric gradients in short baselines by using single frequency measurements. J Aeronaut Astronaut Aviat A 42(4):269-275

International Civil Aviation Organization (2014) International standards and recommended practices. Annex 10 to the Convention on the International Civil Aviation, Amendment 89

Jung S, Lee J (2012) Long-term ionospheric anomaly monitoring for ground based augmentation systems. Radio Sci 47:RS4006

Kelley MC (2008) The Earth's ionosphere, plasma physics and electrodynamics, 2nd edn. Academic Press, Burlignton, MA

Kim M, Choi Y, Jun H, Lee J (2014) GBAS ionospheric threat model assessment for category I operation in the Korean region. GPS Solut 19(3):443-456

Lee J, Pullen S, Datta-Barua S, Enge P (2007) Assessment of ionosphere spatial decorrelation for global positioning systembased aircraft landing systems. J Aircr 44(5):1662-1669

Lee J, Yoon M, Pullen S, Gillespie J, Mather M, Cole R, Rodrigues de Souza J, Doherty P, Pradipta R (2015) Preliminary results from ionospheric threat model development to support GBAS operations in the Brazilian Region. In: Proceedings of ION GNSS+ 2015, Institute of Navigation, Tampa, FL, Sept 14-18, pp 1500-1506

Mayer C, Belabbas B, Jakowski N, Meurer M, Dunkel W (2009) Ionospheric threat space model assessment for GBAS. In: Proceedings of ION GNSS 2009, Institute of Navigation, Savannah, GA, Sept 22-25, pp 1082-1090

Mendillo M (2006) Storms in the ionosphere: patterns and processes for total electron content. Rev Geophys. doi:10.1029/ 2005RG000193 
Pullen S, Park YS, Enge P (2009) Impact and mitigation of ionospheric anomalies on ground-based augmentation of GNSS. Radio Sci 44(1):RS0A21. doi:10.1029/2008RS004084

Rife J, Pullen S (2009) Aviation applications. In: Gleason S, GebreEgziabher D (eds) GNSS applications and methods, Artech House, Ch. 10, pp 245-267

RTCA DO-246D (2008a) GNSS-based precision approach local area augmentation system (LAAS) signal-in-space interface control document (ICD)

RTCA DO-253C (2008b) Minimum operational performance standards for GPS local area augmentation system airborne equipment

Rungraengwajiake S, Supnithi P, Saito S, Siansawasdi N, and Saekow A (2015) Ionospheric delay gradient monitoring for GBAS by GPS stations near Suvarnabhumi airport, Thailand. Radio Sci 50:1076-1085. doi:10.1002/2015RS005738

Saito S, Yoshihara T (2017) Extreme Ionospheric delay gradient associated with plasma bubble. Radio Sci. doi:10.1002/ 2017RS006291

Saito S, Fujita S, Yoshihara T (2012a) Precise measurements of ionospheric delay gradient at short baselines associated with low latitude ionospheric disturbances. In: Proceedings of ION International Technical Meeting 2012, Institute of Navigation, Newport Beach, CA, Jan 30-Feb 1, pp 1145-1150

Saito S, Yoshihara T, Fujita S (2012b) Absolute gradient monitoring for GAST-D with a single-frequency carrier-phase based and code- aided technique. In: Proceedings of ION GNSS 2012, Institute of Navigation, Nashville, TN, Sept 17-21, pp 3055-3065

Schlüter S, Prieto-Cerdeira R, Orus-Peres R, Lam JP, Juan M, Sanz J, Hernández-Pajares M (2013) Characterization and modeling of the ionosphere for EGNOS development and qualification. Paper presented at European navigation conference, Vienna, pp 23-25

Seo J, Lee J, Pullen S, Enge P, Close S (2012) Targeted parameter inflation within ground-based augmentation systems to minimize anomalous ionospheric impact. J Aircr 49(2):587-599

Terkildsen M (2010) GBAS ionospheric threat model evaluation: mid-latitude Australian region. IPS-CR-09-01-P

Woodman RF, LaHoz C (1976) Radar observations of F-region equatorial irregularities. J Geophys Res 81(1):5447-5466

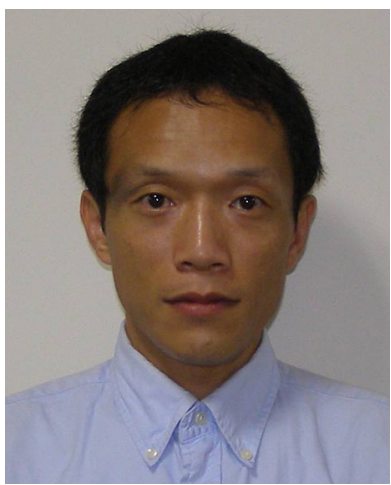

Susumu Saito received his Ph.D. degree in Science from Nagoya University, Japan in 2001. He joined Electronic Navigation Research Institute (ENRI), Japan in 2008. He is involved as a Chief Researcher in a project to develop a groundbased augmentation system (GBAS) suitable for low-latitude regions. $\mathrm{He}$ was the Chairperson of the ICAO APANPIRG Ionospheric Studies Task Force.

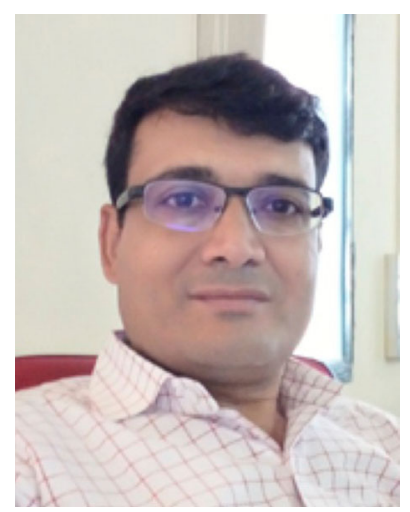

monitoring network.
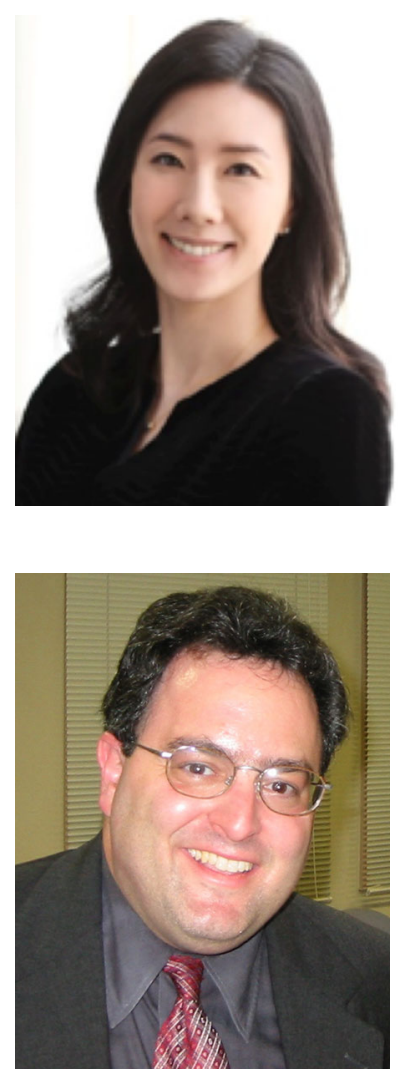

Surendra Sunda received Ph.D. from M. L. Sukhadia University, Udaipur in 2013. He has been working with Airports Authority of India and attached to Space Applications Centre, Indian Space Research Organization, Ahmedabad for the implementation of Indian SBAS-GAGAN. His research activities include positioning, ionospheric, and tropospheric effects on GNSS. He operates and manages the GAGAN ionospheric and scintillation

Jiyun Lee received the Ph.D. degrees in Aeronautics and Astronautics from Stanford University, Stanford, CA, USA, in 2005. She is an Associate Professor in the Department of Aerospace Engineering at Korea Advanced Institute of Science and Technology in Daejeon, Republic of Korea. She has published over 80 research papers. She was awarded the FAA Recognition Award in 2013.

Sam Pullen is the technical manager of the Ground Based Augmentation System (GBAS) research effort at Stanford University, where he received his Ph.D. in Aeronautics and Astronautics in 1996. He has supported the FAA and other transportation service providers in developing system concepts, technical requirements, integrity algorithms, and performance models for GBAS, SBAS, and other GNSS applications and has published well over 100 research papers and articles. He has also provided extensive technical support on GNSS, system optimization, decision analysis, and risk assessment through his consultancy, Sam Pullen Consulting. He was awarded the ION Early Achievement Award in 1999 and became an ION Fellow in 2017. 
Slamet Supriadi received B.Sc and M.Sc. degrees in Faculty of Earth Sciences and Technology from Bandung Institute of Technology, Indonesia in 2015, respectively. He has been involved in ionospheric research for GNSS applications since 2008 at National Institute of Aeronautics and Space (LAPAN) in Indonesia. His research interests include ionospheric correction for positioning, navigation using GNSS, and its augmentation system.

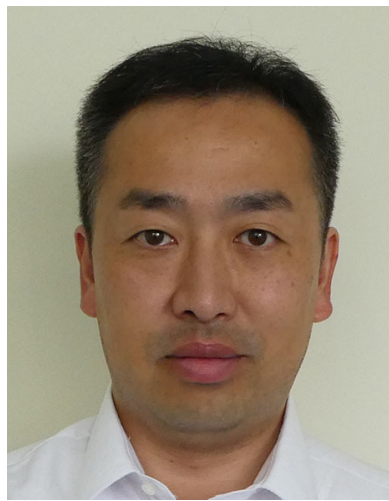

Takayuki Yoshihara is a Chief researcher at ENRI. He received his Ph.D. in GPS application for meteorology from Kyoto University in 2001. He has worked in several projects related to development of GBAS ground subsystem including CAT-III. $\mathrm{He}$ is involved in development of Multi-Constellation and Multi-Frequency GBAS. He is also interested in Air Traffic Management using advanced GNSS-based navigation systems.
Michael Terkildsen is a Senior Research Scientist with Space Weather Services, Australian Bureau of Meteorology, with primary responsibility for GNSS-related research and development. He received his Ph.D. in ionospheric physics from the University of Newcastle (Australia) in 2003. His current research interests include real-time ionospheric modeling for precise GNSS applications and development and implementation of space weather services supporting aviation.

Frédéric Lecat received the M.S. degree in civil aviation and electronics engineering from the ENAC aviation academy, France in 1996. As a Regional Officer Communications, Navigation, and Surveillance in the ICAO Asia-Pacific Office since 2013, his responsibilities include the Secretariat of the Asia-Pacific Ionospheric Study Task Force and the Asia-Pacific PBN Implementation Coordination Group. 